\title{
New Directions in Theorising Social Accountability?
}

\author{
Niraja Gopal Jayal
}

\begin{abstract}
1 Introduction
In classical democratic theory, the justification for accountability related almost exclusively to elected representatives. In contemporary governance thinking, by contrast, the objects of accountability initiatives quite centrally, if not primarily, include non-elected public bureaucracies. This is not particularly surprising given the blurring, in recent times, of the line between the political and the administrative. The enlargement of bureaucracies and the often collaborative nature of their relationship with the political executive have made it difficult to attribute particular actions to either.
\end{abstract}

The conceptual moorings of the idea of accountability are to be found in two affinal traditions: first, the old public administration literature and its more recent avatar, the new public management; and second, the governance paradigm in which it appears, in a grander claim, as the magic formula to resolve most if not all problems of the public sector. However, in the neo-liberal context of complex relationships between public agencies, citizens re-designated as consumers or users, and the not necessarily public producers and/or providers of services, neither of these ideological frameworks provides a satisfactory account of the markers of accountability in general, or of how its adequacy or otherwise in particular areas such as service delivery may be benchmarked.

It is useful to consider how the study, 'Modes of Service Delivery, Collective Action and Social Accountability', that has produced the articles in this IDS Bulletin, is attempting to address these crucially important questions.

\author{
2 Accountability: an undistinguished conceptual \\ history and a legacy of unanswered questions \\ Outside of the realm of democratic theory, \\ academic discourse on accountability has \\ conventionally belonged to the discipline of Public \\ Administration, in which it acquired a meaning \\ extending the early financial connotations of the \\ term. Largely preoccupied with internal modes of \\ accountability - such as channels of authority, \\ control, reporting and performance evaluation - the \\ external forms of accountability recognised in this \\ perspective, were confined to what subsequently \\ came to be called horizontal accountability, through \\ institutions such as the ombudsman or judicial \\ review, although occasionally also including media \\ scrutiny and pressure group activity (Smith 1991).
}

More recently, accountability concerns have been imported into the New Public Management (NPM) literature, as part of the debate on public sector reform. ${ }^{1}$ And, of course, in contemporary governance discourse, accountability is found linked to almost every conceivable aspect of 'good governance' from developmental effectiveness to empowerment. It is brandished as the complete and final solution to all governance problems - the chief instrument for combating the 'three-headed monster' of corruption, clientelism and capture (Ackerman 2005). The World Bank's emphasis on social accountability is also essentially from a 'how to' perspective of arriving at generalisable solutions to the problem of accountability.

Mainstream political science literature on the state and society provides two important distinctions: first, that between answerability, or 'the obligation of public officials to inform about and to explain what they are doing' and enforcement, or 'the capacity of accounting 
agencies to impose sanctions on power holders who have violated their public duties' (Schedler 1999: 14); and second, that between vertical (elections and other mechanisms by which citizens control governments) and horizontal (the checks and balances in governmental systems designed to ensure that due process is followed in governmental decision making) accountability (O'Donnell 1999). While vertical accountability refers to the relationship between the citizen and the state, horizontal accountability is broadly internal to the state structure itself.

The new attention to non-state actors - and in particular civil society interventions - has quite rightly qualified the rigid distinction between vertical and horizontal forms of accountability. As Smulovitz and Peruzzotti (2000) have suggested, civil society groups represent new forms of accountability claims, neither vertical nor horizontal, because the agents are neither citizens (using vertical mechanisms such as voting and elections) nor other organs of the state (providing checks and balances). The mode of societal accountability sponsored by civil society organisations, social movements and media, often in collaboration with each other, uses voice rather than the vote. It remains vertical but - unlike individual citizens - it does not need to wait for elections to be announced; it can be catalysed 'on demand' as and when the situation requires such mobilisation; and it can be directed towards single issues, policies or functionaries. Civil society initiatives can also occasionally generate hybrid forms of accountability that bridge the horizontal-vertical divide when, though directly aimed at achieving vertical accountability, they additionally cause intra-state horizontal accountability mechanisms to be energised, thus creating conditions for greater accountability than may have been possible purely through the vertical route (Goetz and Jenkins 2001).

The broad picture that emerges from the not particularly voluminous literature on the subject suggests that the actors seeking accountability, as also those from whom accountability is sought, have multiplied. Those seeking accountability now include not only individual citizens but also civil society groups, non-governmental organisations (NGOs) and social movements. Accountability, moreover, appears to be a cause adopted by very dissimilar groups - from NGOs broadly sympathetic to neo-liberalism to the social movements which strongly oppose it. Both, Baviskar (2006) tells us, are equally ardent campaigners for accountability, though we do not exactly know the practical implications of this difference. Does, for instance, the demands for accountability lose its radical edge if it attracts ideologically diverse, indeed sharply opposed, sponsors?

As for those to whom demands of accountability are addressed, their number too has grown and is extremely diverse. They include not just state agencies, but also corporations and civil society organisations. Despite its self-righteousness in the watchdog role, it has assumed in holding the state to account, how accountable is civil society itself? If NGOs do their funders' bidding, and their accountability is to the funding agencies alone, can they really be described as 'civil society'? Servicedelivery NGOs, in particular, often function as state franchises and public-service contractors, as well as implementers of state-designed and state-funded development programmes where states themselves lack the capacity to implement. In the performance of these roles, the NGO necessarily becomes accountable to the state. Indeed, some of the accountability talk emanating from civil society can be deeply depoliticising, insofar as it pits (virtuous) civil society against (evil) politics, and superciliously positions civil society as a 'clean' alternative to the 'dirty' business of politics.

An aspect of the accountability question that remains under-investigated is that of the instruments of accountability. In India, the Right to Information Act 2005 represents one such instrument. As a mechanism to bring about greater transparency, this is a legislation that can at best facilitate mobilisation and action for accountability. However, there is often a tendency to use the terms accountability and transparency interchangeably, which hints at a conceptual confusion, but one that has practical consequences: an initiative that is effective in securing transparency is assumed to substitute for accountability, as the instrument becomes the goal. It tends also to obscure the next steps in the process, of what to do with such information as is gleaned through the Right to Information Act to take it forward to grievance redressal. The state machinery for the redressal of public grievances is far from perfect, but it tends not to receive the attention it deserves if the transparency gains are to translate into accountability benefits. What are the chief instruments of accountability; how are they related to each other as to the larger objective of achieving 
accountable governance; which instrument is likely to be most effective, and in which context? We do not yet have sufficient clarity on these issues.

\section{Modes of service delivery, collective action and social accountability \\ 'Modes of Service Delivery, Collective Action and}

Social Accountability' is an ambitious study that seeks to compare three large metropolitan cities - Mexico City, São Paulo and Delhi - in as many countries of the South. The project is not confined to looking simply at how forms of collective action result in improved service delivery. Instead, through a focus on two areas - health and social assistance - it seeks to understand how particular types of reform in service delivery are enabling of collective action; how collective action intervenes not only in the delivery mechanism but also at the stage of influencing policy formulation; and, most importantly, how social accountability is enhanced through such interventions. The hypothesis is that reforms that are 'voice-oriented' (e.g. that enable decentralisation and institutionalise participation) and allow scope for collective actors to participate in the negotiation of policies, as opposed to those that are 'choiceoriented' (e.g. market mechanisms), are more likely to increase access to and quality of services, as also societal accountability of the service providers. Social accountability is in turn defined as the institutionalisation of 'durable societal controls over policies, including over their implementation or uptake by providers' (see Joshi, this IDS Bulletin), and therefore focuses on more than merely community mobilisation for securing public benefits.

\subsection{Is accountability more than an outcome?}

The study conceptualises accountability in terms of (a) the social, i.e. collective, dimension of accountability, in opposition to individual accountability; and (b) the instruments used by these actors - such as monitoring, exposing wrongdoing, etc. The literature emanating from the World Bank defines social accountability in ways that largely cohere with this research, as a form of accountability that relies on civic engagement, encompassing actions by citizens, communities, the media and NGOs. But that literature further distinguishes between types of social accountability based on the actors involved; the collaborative or conflictual mode of such action; the incentive structures based variously on punishment and reward; the depth of involvement of civil society from the planning stage onwards; and the purpose of accountability in terms of adherence to rules or performance. Whether or not the research frame of this project subscribes to any of those assumptions is not known, but it is worth asking whether this framework yield an alternative, and more robust, theorisation of accountability, instead of viewing it only as an outcome, albeit an institutionalised one, of collective action?

\subsection{Is accountability to be inferred or} independently measured?

Following from this, there is arguably room for greater clarity about whether social accountability is to be inferred from the impact of collective action on service providers, or whether it is a variable to be independently measured. While a great deal of careful thought has gone into the methodological aspects (see Houtzager and Acharya, this IDS Bulletin), little is said about how social accountability will be identified and measured. In the discussion of the third analytic level - the level of cross-sectional analysis of the health and social assistance catchment areas in low-income neighbourhoods - actual improvements in policy implementation and service outputs are rightly taken as measures of improved service delivery. However, it remains unclear whether the concept of social accountability is merely implicit in these improved outputs or has an independent analytical status, and if so how it will be measured. This becomes especially important in view of the explicit elaboration of accountability in terms of institutionalised and durable controls over both policy and its implementation, and the equally explicit reluctance to view it as particular public benefits extracted by community mobilisation.

\subsection{Diverse impacts of collective action: policy} shifts and/or improved service delivery?

There are at least three types of possibilities exemplified by the health and social assistance cases in the study. These are: low levels of collective action; impact of collective action in terms of effecting policy shifts rather than improved service delivery; and impact of collective action on improved service delivery. The Mexican cases appears to illustrate the first, as we are told that participation by citizens whether as users of services or as lacking access to them - is weak, and such measures of social protection as have been initiated are the result of the perception of bureaucrats and academics that the health system has under-performed (see GómezJauregui, this IDS Bulletin). 
Second, the impact of collective action may, as in the case of Brazil, be manifest in policy shifts rather than in an improved quality of service delivery. The emphasis on collective action as participation in the negotiation of the content of public sector reform and policy is unusual and important. Nevertheless, there is no analytical explanation for why policy shifts alone - rather than in combination with actual improved delivery or access - should fully satisfy the test of social accountability.

Probably the most interesting case for the research question is the use of a new national law, the Right to Information Act 2005, by the NGO Parivartan to expose corruption and bring about greater transparency in the Public Distribution System (PDS) in Delhi (see Pande, this IDS Bulletin). However, even this article does not signal whether this has actually reduced corruption in the PDS or improved access, or even whether an appeal has been made to the appellate agency or if that agency has acted to punish those responsible. This part of the story is simply missing in what is arguably the 'best' case for the study.

A recent study, 'Democracy and Well-Being in India' (Chandhoke 2005), suggested that while a political and governmental commitment to welfarism, and an active civil society are crucially important, civil society mobilisation by itself is often ineffectual without judicial activism. The public interest litigation on the Right to Food in India (Pande, this IDS Bulletin) bears this out. Given the interest in institutions (e.g. in how institutions influence collective action) in this study, it would be useful to differentiate, and theorise these differences, between the institutions to which collective action is addressed.

\subsection{Effective service delivery without accountability?}

A set of recent studies on India have documented successful experiments in making service delivery effective without collective action playing a role, and without necessarily enhancing social accountability (Chand 2006). A variety of factors - political and institutional - have contributed to these successes, not all of which are or have been sustainable in the longer term. The 'Modes of Service Delivery, Collective Action and Social Accountability' study does in fact mention the role of political party competition in both national and local-level reforms, and the Brazil cases pay some attention to the political dynamics of these (see Dowbor and Houtzager, this IDS Bulletin). Nevertheless, there is a strong case for considering 'deviant' cases of effective service delivery, facilitated by the top-down mobilisation of political support (Houtzager, this IDS Bulletin). A comparison between human development performance in the Indian states of Tamil Nadu and Karnataka documents quite convincingly the role of institutionalised welfarism in Tamil Nadu, where political competition and alternation of power between the two major parties has ensured that the welfare gains of one regime are not overturned by another (Goyal 2006: 320).

Normatively, of course, effective and responsive service delivery is to be preferred in combination with stable patterns of social accountability. But it is hard to disregard examples of political commitment and administrative competence, without much civil society activism, providing efficient public services.

\subsection{Civil society: service provider and watchdog?}

The role of civil society organisations in service delivery raises an important question: how do we think about social accountability in situations where civil society organisations are themselves the service providers? In most of the cases selected for study, the reforms have implied privatisation. It is only in Brazil (in the area of health) that the research includes a case representing the broader process of 'pluralisation' with non-profit organisations also participating in service delivery. This may introduce a bias into the research, for in India though not in the cases selected for research - the involvement of NGOs in service provision is fairly common. The exclusion of such cases, by implication, excludes therefore the critical question of what happens to accountability when civil society organisations themselves become the producers or providers of services?

\subsection{Instruments of accountability}

A striking case in the research is that of the use of the Right to Information Act by the NGO Parivartan in exposing the corruption and misappropriation of subsidised food meant for the poor from the PDS in Delhi. In sharp contrast to this success in using the Right to Information Act (RTI) as an instrument of accountability in Delhi, there is the case of the PDS in Tamil Nadu, whose almost model efficiency is a result of political commitment and administrative competence. Though the RTI in that state makes a specific reference to the PDS, NGOs in Tamil Nadu have not needed to step into this arena, possibly 
because 'electoral outcomes are determined on the floor of the fair price shops' (Venkatsubramanian 2006: 287). There are scores of other successful instruments - including citizens' report cards - and this research could make an important contribution by simultaneously and separately documenting the varieties of instruments of social accountability uncovered in the various case studies. Smulovitz and Peruzzotti, among others, have mentioned the role of the media, and it definitely played a role in Parivartan's campaign against the PDS. Other empirical studies may possibly provide more evidence of this.

\subsection{Multi-level accountability?}

The study discussed in this IDS Bulletin is sensitive to the possibly distinct dynamics of national-level and local-level policies, and this is arguably an issue also worth thinking about in relation to accountability. Much activism for accountability takes place at the local level, and sometimes around a single issue, and it is not always clear if these initiatives remain confined to the local, and under what conditions they can be replicated and scaled-up. What is needed is a perspective that can relate these levels to each other and situate them within a broader analytical framework.

\section{Theorising accountability}

It is clear that accountability has, in recent years, moved from being the supply side of a right, closer to being articulated as a right in itself. Though, as we have already noted, the RTI is frequently and mistakenly assumed to stand in for accountability itself, it is obvious that information is only an instrument towards the larger objective of securing accountable governance. It is possible that the coming years will see accountability projected as a citizens' right in itself, even if as a 'manifesto' right (O'Neill 1986), rather than one that can be enshrined as such in law.

The same reasons that make it impossible for accountability to be enshrined as a legal right also indicate why the principle of accountability is frequently an emanation from social practice rather than from theory. Though implicit in the very fundamentals of democratic theory, it is hard to design outside of institutional structures. The advancement of this goal is the task of social and political action, rather than of theory itself. Political scientists can, of course, reflect on the comparative experiences of such practices in various countries of the world; they can try and explain why certain types of accountability initiatives are more effective and in which contexts; and they can also indicate policy instruments that could enhance accountability. Ultimately, however, accountability is something that citizens seek and achieve from governments that are willing to be accomplices in the broader objectives of the democratic project.

Following from this, finally, it is evident that while the emphasis on civil society activism rightly draws our attention to the necessarily social (as opposed to individual) character of accountability initiatives, it is important not to forget that state agencies and state personnel, which are the targets of these initiatives, have also, willingly or otherwise, to be a participant in these - whether by their role in the passage of laws such as the Right to Information and the drafting of Citizens' Charters or by their occasionally reluctant capitulation to these.

\section{Notes}

1 In some quarters of NPM, of course, there is resistance to this on the grounds that the inordinate assigning of blame on public functionaries is 'dysfunctional' because it

emphasises the negative aspects of accountability and will therefore encourage 'more buckpassing and scapegoating by both politicians and appointed officials' (Thomas 1998: 353). 


\section{References}

Ackerman, John M. (2005) 'Social Accountability in the Public Sector: A Conceptual Discussion', Social Development Paper 82, March, Washington DC: World Bank

Baviskar, Amita (2006) 'Is Knowledge Power?: The Right to Information Campaign in India', unpublished mimeo

Chand, Vikram K. (ed.) (2006) Reinventing Public Service Delivery in India: Selected Case Studies, New Delhi: World Bank and Sage

Chandhoke, Neera (2005) Democracy and Well-Being in India, Geneva: United Nations Research Institute for Social Development (UNRISD)

Goetz, Anne Marie and Jenkins, Rob (2001) 'Hybrid Forms of Accountability: Citizen Engagement in Institutions of Public Sector Oversight in India', www.bbk.ac.uk/polsoc/staff/academic/rob-jenkins/ accountability (accessed January 2008)

Goyal, Sangeeta (2006) 'Human Development in Tamil Nadu and Karnataka: A Comparison', in Vikram K. Chand (ed.), Reinventing Public Service Delivery in India: Selected Case Studies, New Delhi: World Bank and Sage

O'Donnell, Guillermo (1999) 'Horizontal

Accountability in New Democracies', in Andreas Schedler, Larry Diamond and Marc Plattner (eds),
The Self-Restraining State: Power and Accountability in New Democracies, Boulder, Colorado: Lynne Rienner

O'Neill, Onora (1986) Faces of Hunger, London: Allen and Unwin

Schedler, Andreas (1999) 'Conceptualizing Accountability', in Andreas Schedler, Larry Diamond and Marc Plattner (eds), The SelfRestraining State: Power and Accountability in New Democracies, Boulder, Colorado: Lynne Rienner Smith, Thomas B. (1991) 'The Comparative Analysis of Bureaucratic Accountability', Asian Journal of Public Administration 13.1: 93-104

Smulovitz, Catalina and Peruzzotti, Enrique (2000) 'Societal Accountability: The Other Side of Control', Journal of Democracy 11.4, October Thomas, Paul G. (1998) 'The Changing Nature of Accountability', in Guy Peters and Donald J. Savoie (eds), Taking Stock: Assessing Public Sector Reforms, Montreal and Kingston: Canadian Centre for Management Development and McGillQueen's University Press

Venkatsubramanian, A.K. (2006) 'The Political Economy of the Public Distribution System in Tamil Nadu', in Vikram K. Chand (ed.), Reinventing Public Service Delivery in India: Selected Case Studies, New Delhi: World Bank and Sage 


\section{Institute of Development Studies IDS Knowledge Services}

\section{Start your search with us}

Welcome to the IDS Information Department's family of Knowledge Services. Between them they cover the full spectrum of social and economic development topics and make it easier to access information from a wide range of sources.

- British Library for Development Studies: Europe's largest research collection on economic and social change in developing countries. http://blds.ids.ac.uk/

- BRIDGE: supporting gender advocacy and bridging gaps between theory, policy and practice with accessible and diverse gender information.

www.bridge.ids.ac.uk

- Siyanda: an online database of summarised gender and development materials from around the world with links to full-text resources.

www.siyanda.org

- Eldis: sharing the best in development, policy, practice and research. www.eldis.org

- Governance and Social Development Resource Centre: access to the best thinking on governance, conflict and social development. www.gsdrc.org

- Health \& Development Information Team: providing high quality, accessible information on health and development.

www.ids.ac.uk/go/knowledge-services/services/health-and-development-information

- id21: communicating UK-sourced international development research to policymakers and practitioners worldwide.

www.id21.org

- Knowledge Partnerships: addressing knowledge management and communications challenges.

www.ids.ac.uk/go/ids-knowledge-services/our-services/knowledge-partnerships

- Livelihoods Connect: facilitating knowledge sharing and networking to enable the practical implementation of Sustainable Livelihoods Approaches. www.livelihoods.org

\section{www.ids.ac.uk/info}




\section{Institute of Development Studies Postgraduate Development Studies}

IDS offers the following postgraduate programmes:

One-year MAs in

- Development Studies

- Poverty and Development

- Science, Society and Development

- Gender and Development, run jointly with the University of Sussex

- Governance and Development

- Participation, Power and Social Change

- Globalisation and Development (new for 2008)

Plus

- A two-year MPhil in Development Studies

- The supervision of students working for the degree of DPhil by research

\section{DS Institute of}

Development Studies

Further information on all IDS teaching and training activities is available from: The Teaching and Training Unit, Institute of Development Studies at the University of Sussex, Brighton BN1 9RE, UK 